\title{
Retained placenta associated with Escherichia coli infection in a dairy cow
}

\begin{abstract}
Retained placenta is one of the complications associated with parturition in dairy cows. A 4year old Friesian-kedah cross cow weighing 400kg was presented to the large animal unit University Veterinary Hospital, Universiti Putra Malaysia, with the complain of retained placenta 9 days prior to presentation. Clinical findings were pyrexia, congested mucous membranes and serosanguineous discharge with fetid odour from the vulva. Haematology and biochemistry findings showed an increase in packed cell volume, monocytosis, hyperglobulinaemia, hyperproteinemia, hypernatremia, hyperchloridaemia and increased level of creatine kinase. Bacterial culture from the swab samples of the vaginal discharge revealed growth of Escherichia coli. The retained placenta was manually removed by gentle traction and the uterus was lavaged using normal saline $(0.9 \% \mathrm{NaCl})$ followed by an intrauterine infusion of Oxytetracycline hydrochloride L.A $(20 \mathrm{mg} / \mathrm{kg})$. Systemic intramuscular injections of Oxytetracycline hydrochloride $(20 \mathrm{mg} / \mathrm{kg}$ Stat), Flunixine meglumine $(1.1 \mathrm{mg} / \mathrm{kg})$ and multivitamin $(10 \mathrm{mg} / \mathrm{kg})$ were administered. The prognosis was good after a follow up visit one week later. Retention of placenta following parturition is usually associated with bacterial pathogens. Therefore, prompt intervention in cases exceeding 24 hours post partum is important in order to avert the incidence of uterine infections that will threaten heard fertility.
\end{abstract}

Keyword: Retained placenta; Dairy cow; Uterine infection; Escherichia coli 